\title{
O ENSINO DE CIÊNCIAS E MATEMÁTICA NOS ANOS INICIAIS VISANDO À APRENDIZAGEM SIGNIFICATIVA
}

Zenar Pedro Schein ${ }^{1}$ Maria Eloisa Farias ${ }^{2}$

\begin{abstract}
RESUMO
Investigar a contribuição da educação para o desenvolvimento regional é papel de pesquisadores preocupados com essa relação. Para refletir sobre isso é importante destacar a função da educação nesse contexto envolvendo a análise sobre a prática docente dos professores. Nesse sentido, este artigo objetiva analisar se a prática unidocente de professores visa à aprendizagem significativa dos alunos. Por isso, no ano de 2012, desenvolveu-se uma tese investigativa envolvendo o ensino de Ciências e Matemática nos Anos Iniciais do Ensino Fundamental em escolas públicas municipais de Taquara/RS, localizada na região Vale do Paranhana. Como resultado, observou-se que diversos aspectos metodológicos, entre eles, a contextualização e a apresentação de novas formas de ensino, a valorização do conhecimento demonstrado pelo aluno, o ensino através da prática, entre outros, tendem ao desenvolvimento de uma aprendizagem significativa nos Anos Iniciais. Conclui-se, com base nos resultados encontrados, que os aspectos metodológicos utilizados pelos professores pode ir ao encontro da aprendizagem significativa e promover o conhecimento reflexivo por parte do aluno.
\end{abstract}

Palavras-chave: Aprendizagem significativa. Prática Unidocente. Ensino de Ciências e Matemática.

\section{ABSTRACT}

Investigating possibilities to improve regional development is the role of researches who are concerned with this demand. To have a reflection about this, it is important to highlight the function of education in this context, including the analysis of teachers practice. This way, this article aims to analyse whether the uniteaching practice of teachers claims a meaningful learnship from the students. Thus, during the year of 2012, an investigative

\footnotetext{
${ }^{1}$ Mestre em Educação em Ciências e Matemática. Doutorando em Ensino de Ciências e Matemática da Universidade Luterana do Brasil (Ulbra)/RS. Professor e Coordenador do Curso de Matemática nas Faculdades Integradas de Taquara (Faccat)/RS. pedroschein@uol.com.br.

2 Doutora em Educação. Professora do PPGECIM/Ulbra/RS. mariefs10@yahoo.com.br.
} 
thesis was developed including the teaching of Science and Math for the first years of elementary school, in municipal public schools in Taquara/RS, in the Vale do Paranhana region. As a result, it was observed that various methodologic aspects, among them, contextualization and presentation of new ways of teaching, valorization of the knowledge showed by the student, teaching through practice, and the others, tend to the development of a meaningful learnship in the first years. The conclusion, based on the obteinad results, is that the methodologic aspects used by the teachers can go on to find the meaningful learnship and promote the reflexive knowledge by the student.

Keywords: Meaningful learnship. Uniteaching practice. Science and Math teaching.

\section{INTRODUÇÃO}

O estudo que envolve o trabalho do professor da educação básica e do Ensino Superior reflete a ideia de que a formação do educador precisa estar em constante atualização, independentemente do nível em que o docente está atuando.

Assim, não é diferente com os professores dos Anos Iniciais do Ensino Fundamental, pois o desafio do ensino de Ciências e Matemática nesse período escolar exige que o docente esteja cada vez mais preparado, dinâmico, criativo e capaz de realizar uma reflexão sobre sua ação, respondendo às necessidades educativas atuais.

Em parte, essas exigências são produzidas pela velocidade da informação e pelo avanço das tecnologias que chegam ao contexto educacional, pressionando o professor a atualizar-se, forçando a busca de estratégias novas e diversificadas para tornar as aulas mais atraentes e significativas. Com isso, é possível favorecer o desenvolvimento regional através de uma educação de qualidade.

Sendo assim, busca-se o aprofundamento na temática ensino e unidocência no cenário municipal, considerando que o professor atuante nos primeiros anos da escolarização trabalha com vários campos do conhecimento em que pratica uma forma de docência que pode repercutir intensamente na formação das crianças. Nesse contexto, para Krasilchik (2000), o ensino, de forma geral, reflete o momento político, econômico e cultural da sociedade, o que justifica essa investigação.

Como desafio para desenvolver essa pesquisa, apresenta-se o seguinte questionamento: "Como a prática unidocente no ensino de Ciências e Matemática tem contribuído para a aprendizagem significativa nos Anos Iniciais do Ensino Fundamental em escolas municipais de Taquara/RS?". Objetiva-se também investigar o perfil dos professores unidocentes, as características metodológicas que visam à aprendizagem significativa do aluno e sua aplicabilidade em sala de aula.

\section{ENSINO DE CIÊNCIAS E O ENSINO DE MATEMÁTICA NOS ANOS INICIAIS}

Na educação brasileira atual, o professor unidocente trabalha com todas as disciplinas nos Anos Iniciais do Ensino Fundamental.

De acordo com a realidade desses educadores, alguns têm formação de nível médio e outros de nível superior e, possivelmente, essa formação pode fazer a diferença 
na aprendizagem do aluno. Para Kindel (1998, p. 47), muitos professores de Ciências

[...] não possuem qualificação para o exercício desta disciplina, por terem passado por um curso de formação precário ou ainda pela impossibilidade de constante atualização. [...] A situação torna-se ainda mais grave nas séries iniciais, quando o professor precisa dominar não só os conteúdos da área de ciências, mas também os de outras áreas.

Nesse sentido, há necessidade de o professor dos Anos Iniciais ter a capacidade de desenvolver uma proposta metodológica que vise à construção do conhecimento do aluno. Para isso, ele precisa estar capacitado e ter condições de desenvolver metodologias de ensino em sala de aula que proponham ao aluno a construção de um conhecimento em um processo ativo. "Partimos do princípio de que se 'aprende' nas séries iniciais, refazendo e reconstruindo o conhecimento num processo ativo, para que a criança possa entendê-lo e compreendê-lo numa dimensão mais global" (FRIZZO; MARIN, 1997, p. 13).

No ensino de Ciências, o professor pode utilizar-se do conhecimento prévio da criança, elaborar metodologias com atividades práticas, envolvendo a observação, a comparação e a sistematização para possibilitar que o aluno organize conclusões.

[...] é necessário que o ensino na área de Ciências aconteça a partir de atividades práticas, onde a criança, a partir destas atividades, seja desafiada a vivenciar o processo de reconstrução do conhecimento reelaborando-o e sistematizando-o numa ação mental, chegando a conclusões, num processo investigativo no qual o conhecimento acontece numa interação constante entre prática, ação, observação, comparação e sistematização (FRIZZO; MARIN, 1997, p. 14).

Da mesma forma, no ensino da Matemática, é necessário fazer com que o professor tenha a capacidade de desenvolver suas aulas com alguma metodologia que incentive a criança ao gosto pela aprendizagem, pois "os primeiros anos da escola são muito importantes porque é nesse momento que a criança entra em contato, pela primeira vez, com a Matemática sistematizada" (KOCH; RIBEIRO, 1998, p. 39).

Enfim, o professor que trabalha com os Anos Iniciais precisa saber que o futuro do seu aluno quanto à compreensão das Ciências e da Matemática vai depender da forma como forem introduzidos nessa aprendizagem.

\section{A APRENDIZAGEM SIGNIFICATIVA NO ENSINO FUNDAMENTAL}

Na atualidade, faz-se necessário discutir sobre teorias de aprendizagem que objetivam promover a construção do conhecimento do aluno, pois "[...] não é mais possível conceber a aprendizagem como uma atividade apenas de reprodução ou cumulativa" (POZO; CRESPO, 2009, p. 22).

No cotidiano da sala de aula, o aluno está disponível ao processo educacional de ensino e de aprendizagem ancorado por teorias de desenvolvimento cognitivo que deveriam ser compreendidas e colocadas em prática pelos professores, porque "a tarefa do professor consiste, a grosso modo, em transformar a matéria que ensina para que os alunos possam compreendê-la e assimilá-la" (TARDIF, 2005, p. 120, grifos do autor). 
Para que essa tarefa do professor possa ser colocada em prática, existem diversas teorias. Uma dessas teorias é da aprendizagem significativa construída por Ausubel e amplamente defendida por Moreira (2006; 2008; 2009; 2010). Nesse sentido, a aprendizagem está relacionada à "[...] organização e integração do novo material na estrutura cognitiva"3 (MOREIRA, 2008, p. 1). No entanto, a aprendizagem significativa vai além e aprofunda-se conceitualmente.

Aprendizagem significativa é aquela em que o significado do novo conhecimento vem da interação com algum conhecimento especificamente relevante já existente na estrutura cognitiva do aprendiz com um certo grau de estabilidade e diferenciação (MOREIRA, 2009, p. 31).

Está intimamente articulada com o conhecimento prévio, ou seja, defende-se que a aprendizagem vai ocorrer se o conhecimento adquirido antes do processo em estudo for levado em conta.

[...] a criança não é uma 'página em branco' sobre a qual se pode imprimir um saber; ela possui concepções e a evolução destas é que constituirá um nível de conhecimento cada vez mais operatório [...]. Isso implica ações educativas ou culturais que levem em consideração as representações, com o intuito de transformá-las para, no fim, levar a constructos mais próximos da realidade e de melhor desempenho na resolução de futuros problemas (GIORDAN; VECCHI, 1996, p. 138).

É por meio do conhecimento prévio que o aluno consegue estabelecer pontes cognitivas que podem favorecer relações de aprendizagem articuladas ao novo conhecimento.

Os organizadores prévios podem tanto fornecer ideias âncora relevantes para a aprendizagem significativa do novo material, quanto estabelecer relações entre ideias, proposições e conceitos já existentes na estrutura cognitiva e aqueles contidos no material de aprendizagem (MOREIRA, 2008, p. 2, grifo do autor).

É papel fundamental do professor levar em consideração o conhecimento prévio do aluno.

Sua colaboração fundamental consistiu na concepção de que a aprendizagem deve ser uma atividade significativa para a pessoa que aprende e tal significação está diretamente relacionada com a existência de relações entre o conhecimento novo e o que o aluno já possui (CARRETERO, 1997, p. 16).

A aprendizagem significativa é um processo por meio do qual uma nova informação interage de forma substantiva (associar o conceito com algo que tenha um significado próximo) e não arbitrária (quando é aceita pela comunidade científica e não criada pelo professor), pois uma das condições para que ocorra a aprendizagem significativa

3 "Estrutura cognitiva significa, portanto, uma estrutura hierárquica de conceitos, os quais são
representações de experiências sensoriais do indivíduo" (MOREIRA, 2006, p. 153, grifo do autor). 
"[...] é que o aprendiz manifeste uma disposição para relacionar de maneira substantiva e não-arbitrária o novo material, potencialmente significativo, à sua estrutura cognitiva" (MOREIRA, 2006, p. 156). Isso significa que é necessário que o aprendente consiga relacionar o novo conhecimento com o conhecimento antigo.

Assim, a aprendizagem significativa ocorre quando novos conceitos, ideias, proposições interagem com outros conhecimentos relevantes e inclusivos, claros e disponíveis na estrutura cognitiva, sendo por eles assimilados, contribuindo para sua diferenciação, elaboração e estabilidade (MOREIRA, 2008, p. 2, grifo do autor).

Entretanto, para ocorrer a aprendizagem significativa, é necessário existir os subsunçores específicos existentes na estrutura cognitiva do indivíduo.

Segundo Ausubel, a essência do processo de aprendizagem significativa reside em que idéias expressas simbolicamente são relacionadas de uma maneira não-arbitrária e não-literal com aquilo que o aprendiz já sabe, ou seja, com algum aspecto existente, e especificamente relevante, de sua estrutura cognitiva preexistente, como uma imagem, um símbolo já significativo, um conceito ou uma proposição. Este aspecto já existente na estrutura cognitiva e que pode ser um conceito, uma proposição, uma imagem, um símbolo, enfim um conhecimento específico, com pelo menos alguma clareza,estabilidade e diferenciação é o que se chama de subsunçor (MOREIRA, 2009, p. 32, grifo do autor).

Os subsunçores existentes na estrutura cognitiva, advindos dos organizadores prévios, são os conhecimentos científicos que fazem a ponte entre o conhecimento que já existe e o conhecimento final. Para Ausubel, a principal função do organizador prévio é a de servir de ponte entre o que o aprendiz já sabe e o que ele deve saber, a fim de que o material possa ser aprendido de forma significativa (MOREIRA, 2006, p. 155).

Assim, o professor, investindo em um processo para que se efetive uma aprendizagem significativa, pode possibilitar ao aluno a aquisição da cultura da rejeição de verdades prontas, de certezas já definidas e dedefinições absolutas.

\section{METODOLOGIA}

A pesquisa apresenta uma abordagem quali-quantitativa, utilizando a forma de estudo de caso, com informações coletadas na bibliografia da área, tendo como instrumentos de coleta de dados: documentos, entrevistas, questionários com perguntas abertas e fechadas, registros no diário de bordo do pesquisador, observação in loco da prática docente e visitas agendadas.

Em 2012, realizou-se a coleta de dados em sete escolas públicas municipais de Taquara/RS, envolvendo os professores que ensinam Ciências e Matemática nos Anos Iniciais do Ensino Fundamental. Participaram cinco professores de cada escola, um de cada ano, totalizando trinta e cinco unidocentes. 


\section{ANÁLISE DOS DADOS}

Durante as visitas às Escolas, observou-se uma aula de cada ano envolvendo Ciências e Matemática e foram aplicados questionários aos professores dessas turmas. O objetivo foi conhecer o perfil do professor unidocente que trabalha Ciências e Matemática nos Anos Iniciais do Ensino Fundamental em escolas públicas municipais de Taquara/RS.

O pesquisador observou que todos os professores participantes são mulheres e, a partir desse momento, tratar-se-á como professoras. Dessas, 17\% têm até 30 anos de idade e $83 \%$ possuem mais de 30 anos.

Outro fato que caracteriza as 35 professoras unidocentes participantes é a cidade de origem. Das participantes da pesquisa, $63 \%$ têm origem na cidade de Taquara, e isso pode auxiliar na relação cultural entre elas e os alunos em sala de aula.

Na sequência, investigou-se a formação dessas professoras, por acreditar-se que a qualificação das mesmas é fundamental no processo do ensino e da aprendizagem das crianças, visando à reflexão sobre a prática educativa. "Por isso é que, na formação permanente dos professores, o momento fundamental é o da reflexão crítica sobre a prática" (FREIRE, 1997, p. 43).

Constatou-se que $34 \%$ das pesquisadas possuem curso de pós-graduação em nível de especialização, estando relacionado com gestão escolar (11\%) e pedagogia com práticas inovadoras de sala de aula (23\%). Do total das pesquisadas, 31\% têm a formação do curso de Magistério em nível do Ensino Médio, 29\% estão cursando a graduação em Pedagogia e 6\% têm o Ensino Superior completo em Pedagogia.

Para saber da prática docente de cada professora, apresenta-se o Quadro 1, con-

\begin{tabular}{|l|c|c|c|c|c|c|}
\hline \multicolumn{1}{|c|}{ CATEGORIA } & \multicolumn{5}{c|}{ ANOS } & $\%$ \\
\hline & $1^{\circ}$ & $2^{\circ}$ & $3^{\circ}$ & $4^{\circ}$ & $5^{\circ}$ & \\
\hline Aula expositiva & 5 & 6 & 6 & 5 & 6 & 80 \\
\hline Aula prática & 6 & 6 & 7 & 6 & 7 & 91 \\
\hline Trabalho em grupo & 6 & 7 & 7 & 7 & 7 & 97 \\
\hline Quadro/verde/negro & 4 & 7 & 7 & 6 & 7 & 89 \\
\hline Retroprojetor & 1 & 1 & 1 & 0 & 0 & 8 \\
\hline Video/música/jogos & 6 & 7 & 7 & 6 & 7 & 94 \\
\hline Cartaz/desenho/esquema & 7 & 7 & 6 & 6 & 6 & 91 \\
\hline Livro/apostila & 0 & 2 & 3 & 4 & 4 & 37 \\
\hline Artigo/pesquisa & 3 & 1 & 5 & 5 & 5 & 54 \\
\hline Diálogo/debates & 7 & 6 & 7 & 6 & 6 & 91 \\
\hline Ensino contextualizado & 2 & 2 & 6 & 6 & 5 & 60 \\
\hline Amizade (troca entre alunos) & 6 & 6 & 7 & 7 & 7 & 94 \\
\hline Oficinas & 1 & 1 & 3 & 3 & 2 & 29 \\
\hline Outra & 0 & 2 & 0 & 0 & 0 & 6 \\
\hline
\end{tabular}

Quadro 1: Questão sobre Estratégia Docente

Fonte: Resultado da coleta em campo (2012). 
tendo diversas estratégias utilizadas pelas educadoras de cada ano, a partir do qual é possível observar os indicadores por ano do Ensino Fundamental e a porcentagem total de cada estratégia.

Observa-se que as estratégias aulas práticas, cartaz/desenho/esquema e diálogo/ debate são apresentadas por $91 \%$ das professoras pesquisadas. 0 item vídeo/música/ jogos e a troca entre alunos correspondem a $94 \%$, e o trabalho em grupo é apresentado por $97 \%$, enquanto que $29 \%$ são as estratégias metodológicas de ensino com oficinas, o uso do retroprojetor ou outras identificadas como saídas de campo, o uso do laboratório de informática e o teatro.

Quanto à prática docente, são apresentadas onze categorias que poderiam ser escolhidas. No quadro 2, são apresentados os resultados de cada categoria por ano e, no geral, em porcentagem.

\begin{tabular}{|l|c|c|c|c|c|c|}
\hline \multicolumn{1}{|c|}{ CATEGORIA } & \multicolumn{3}{c|}{ ANOS } & \% \\
\hline & $1^{\circ}$ & $2^{\circ}$ & $3^{\circ}$ & $4^{\circ}$ & $5^{\circ}$ & \\
\hline Compreende o aluno através do diálogo & 7 & 7 & 7 & 6 & 7 & 97 \\
\hline Considerar o nível social & 2 & 3 & 2 & 5 & 4 & 46 \\
\hline Ensinar na prática & 7 & 6 & 7 & 6 & 7 & 94 \\
\hline Contextualizar o ensino & 4 & 3 & 6 & 6 & 6 & 71 \\
\hline Compreender o processo de aprendizagem de cada aluno & 6 & 7 & 7 & 6 & 7 & 94 \\
\hline Evidenciar o conhecimento demonstrado pelo aluno & 4 & 6 & 6 & 7 & 7 & 86 \\
\hline Apresentar novas formas de ensino & 2 & 6 & 6 & 6 & 7 & 77 \\
\hline Exigir disciplina na sala de aula & 6 & 7 & 7 & 6 & 7 & 94 \\
\hline Trabalhar a formação moral de valores do aluno & 6 & 7 & 6 & 7 & 7 & 94 \\
\hline Valorizar o lado humano & 6 & 7 & 7 & 6 & 7 & 94 \\
\hline Utiliza o conhecimento prévio do aluno & 7 & 6 & 7 & 6 & 7 & 94 \\
\hline
\end{tabular}

Quadro 2: Questão sobre Estratégias Metodológicas Docentes

Fonte: Coleta em campo (2012).

É possível destacar que as estratégias metodológicas docentes são variadas, e, entre as categorias apresentadas, $94 \%$ estão baseadas no ensino através da prática. Acredita-se na importância da prática por meio da experimentação porque "la experimentación puede intervenir en la enseñanza siguiendo diferentes modalidades" (SÉRÉ, 2002, p. 357).

Nessa mesma porcentagem, também estão baseadas na compreensão do processo de aprendizagem de cada aluno, no trabalho da formação moral de valores do aprendiz, na valorização do lado humano e na utilização do conhecimento prévio do aprendente e na compreensão do mesmo através do diálogo. Isso denota que existe a prática educativa vinculada com o trabalho envolvendo conteúdos conceituais, procedimentais e atitudinais (ZABALA, 1998).

Observa-se que a prática está ancorada na contextualização (71\%) e apresentação de novas formas e na evidência do conhecimento demonstrado pelo aluno (86\%). Além disso, $46 \%$ das professoras unidocentes considera o nível social do aprendente 
para elaborar suas estratégias didáticas.

O professor em sala de aula necessita ter a clareza de competências para que exista a possibilidade de desenvolver conscientemente as suas aulas objetivando um ensino significativo para o seu aluno.

Perrenoud (2000, p. 14) apresenta dez famílias de competências:

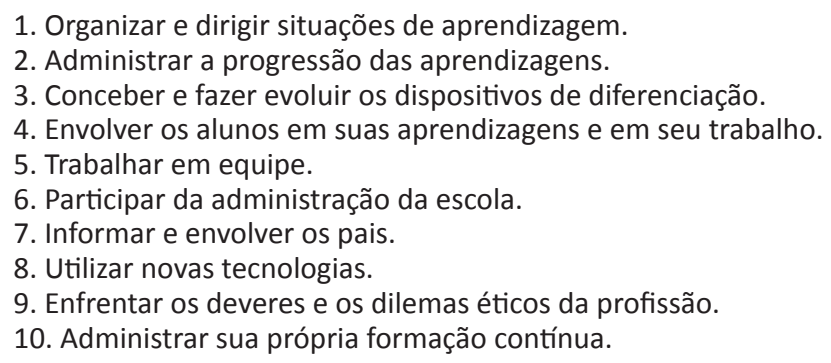

Algumas das competências elencadas acima estão caracterizadas nas estratégias utilizadas pelas professoras. Finalizando, é possível afirmar que essas professoras unidocentes utilizam-se de estratégias diversificadas para trabalhar Ciências e Matemática, baseadas principalmente em aulas práticas, no uso de cartaz/desenho/esquema, no diálogo/ debate, na utilização de vídeo/música/jogos, na troca entre alunos, no trabalho em grupo.

As mesmas professoras pesquisadas têm sua prática docente alicerçada na contextualização do ensino, na apresentação de novas formas de ensino, na valorização do conhecimento demonstrado pelo aluno, no ensino através da prática, na compreensão do processo de aprendizagem de cada aprendente, no trabalho da formação moral de valores do aluno, na valorização do lado humano, na utilização do conhecimento prévio do aprendiz e na compreensão do aluno através do diálogo.

Essas são práticas docentes que muitas das professoras pesquisadas têm em relação ao seu trabalho, o qual está alicerçado em aspectos metodológicos que visam à aprendizagem significativa do aluno.

\section{CONCLUSÕES}

Essa investigação, que teve por base um estudo de campo envolvendo professoras municipais que trabalham nos Anos Iniciais do Ensino Fundamental na cidade de Taqua$\mathrm{ra} / \mathrm{RS}$, permite afirmar que a visita in loco na sala de aula, assim como o acolhimento apresentado pela comunidade escolar, foi indispensável para a realização deste trabalho.

Caracterizar o perfil da professora unidocente municipal foi essencial para que se pudesse conhecer a realidade que envolve o ensino nos Anos Iniciais do Ensino Fundamental desse município.

A prática unidocente no ensino de Ciências e Matemática tem contribuído para a aprendizagem significativa nos Anos Iniciais do Ensino Fundamental em escolas municipais de Taquara/RS por meio de aspectos metodológicos utilizados pelas unidocentes.

É possível destacar aspectos como a contextualização do ensino e a apresentação de novas formas de ensino, a valorização do conhecimento demonstrado pelo aluno, o 
ensino através da prática, a compreensão do processo de aprendizagem de cada aprendente, o trabalho da formação moral de valores do aluno, a valorização do lado humano, a utilização do conhecimento prévio do aprendiz e a compreensão do aluno através do diálogo.

Acredita-se que esta pesquisa possa auxiliar as professoras unidocentes a refletir sobre sua formação, sua prática docente e sua visão metodológica das aulas de Ciências e Matemática ministradas durante os Anos Iniciais do Ensino Fundamental.

Destaca-se que as professoras unidocentes necessitam continuar a articular-se tanto com os colegas dos anos finais do Ensino Fundamental, quanto buscar o conhecimento acadêmico por meio de formação contínua e continuada, visando à melhoria na qualidade do processo de ensino e aprendizagem do Ensino Fundamental público, fator essencial para que ocorra o desenvolvimento regional.

\section{REFERÊNCIAS}

CARRETERO, Mario. Construtivismo e educação. Porto Alegre: Artes Médicas, 1997.

FREIRE, Paulo. Pedagogia da autonomia: saberes necessários à prática educativa. 2. ed. São Paulo: Paz e Terra, 1997.

FRIZZO, Marisa Nunes; MARIN, Eulália Berschorner. O ensino de ciências nas séries iniciais. 3. ed. Ijuí: Unijuí, 1997.

GIORDAN, André; VECCHI, Gerard de. As Origens do Saber: das concepções dos aprendentes aos conceitos científicos. 2. ed. Porto Alegre: Artes Médicas, 1996.

KINDEL, Eunice Aita Isaia. Reflexões sobre o ensino de ciências. In: XAVIER, Maria Luisa Merino; ZEN, Maria Isabel Habckost. O ensino nas séries iniciais: das concepções teóricas às metodologias. 2. ed. Porto Alegre: Mediação, 1998. p. 47-50.

$\mathrm{KOCH}$, Maria Celeste Machado; RIBEIRO, Maria Judith Sperb. Um professor entre o aluno e o saber matemático. In: XAVIER, Maria Luisa Merino; ZEN, Maria Isabel Habckost. $O$ ensino nas séries iniciais: das concepções teóricas às metodologias. 2 . ed. Porto Alegre: Mediação, 1998. p. 39-46.

KRASILCHIK, Myriam. Reformas e realidade o caso do ensino das ciências. Perspectiva, V. 14, n. 1, 2000.

MOREIRA, Marco Antonio. Aprendizagem significativa crítica. 2. ed. 2010. Disponível em: <http://moreira.if.ufrgs.br/apsigcritport.pdf>. Acesso em: 13 jan. 2012.

. Organizadores prévios e aprendizagem significativa. Revista Chilena de Educación Científica, v. 7, n. 2, 2008, p. 23-30. Disponível em: <http://www.if.ufrgs. $\mathrm{br} / \sim$ moreira/ORGANIZADORESport.pdf>. Acesso em: 29 dez. 2012.

. Subsídios teóricos para o professor pesquisador em ensino de Ciências: Comportamentalismo, Construtivismo e Humanismo. Porto Alegre, 2009. Disponível em: <http://www.if.ufrgs.br/ moreira/Subsidios5.pdf>. Acesso em: 29 dez. 2012.

. Teorias de aprendizagem. 3. reimpressão. São Paulo: E.P.U., 2006.

PERRENOUD, Philippe. Dez novas competências para ensinar. Porto Alegre: Artmed, 2000. 
POZO, Juan Ignacio; CRESPO, Miguel Ángel Gómez. A aprendizagem e o ensino de ciências: do conhecimento cotidiano ao conhecimento científico. 5. ed. Porto Alegre: Artmed, 2009.

SÉRÉ, Marie-Geneviève. La enseñanza em la laboratório. ¿Qué podemos aprender em términos de conocimiento práctico y de actitudes hacia la ciência? Enseñanza de las Ciencias, Barcelona, v. 20, n. 3, p. 357-368, 2002.

TARDIF, Maurice. Saberes docentes e formação profissional. 5. ed. Petrópolis: Vozes, 2005.

ZABALA, Antoni. A prática educativa: como ensinar. Porto Alegre: Artmed, 1998. 